\title{
EVOLVING TECHNOLOGY: RECOGNITION AND OPPORTUNITY*
}

Bruce W. Lytle, MD

\section{Editorial note}

The Journal has the responsibility to morph with changes in our specialty. One example of this growth has been the addition to the Journal of a section entitled "Evolving Technology." This section provides a forum for brief communications and original manuscripts that focus on emerging technologies that influence our practice. The same rigorous standards of peer review are applied to these articles as to any other article accepted for publication in the Journal. It does, however, sequester this information into an easily identifiable section of the Journal.

Enabling technology alters the way we do things: sometimes for the better (enduring technology) and sometimes not for the better (evanescent technology). Occasionally, new technologies that do not endure are steps in the direction of advances that will ultimately become part of our therapeutic options. Whereas new pharmacologic agents can usually be rapidly dispersed and their use can be well described in text, advances in technology are more complex to disseminate. Ideally, one would like to minimize the "learning curve" that accompanies technologic advances. The impact of this learning curve may be found in articles that have assessed the efficacy of new surgical techniques as a function of time. These articles frequently focus on the experience within a single or a limited number of institutions. When consideration is given to the rate at which expertise is acquired among multiple institutions, the scatter becomes greater, progress slower, and the attendant morbidity higher.

The accompanying comments from Dr Bruce Lytle describe one approach to the more rapid and controlled dissemination of technologic information and a method for the acquisition of expertise. This approach is laudatory and should pave the way for similar demonstration projects.

Andrew S. Wechsler, MD

Editor

$T^{\mathrm{h}}$ he pace of technologic change in cardiothoracic surgery is accelerating. As changes in instrumentation, devices, and concepts of invasive treatment continue to evolve and become more diverse, the technical education of cardiothoracic surgeons becomes increasingly difficult. Few residency programs contain faculty experienced in the spectrum of current and future tech-

From the Department of Thoracic/Cardiovascular Surgery, The Cleveland Clinic Foundation, Cleveland, Ohio.

*This editorial is being published simultaneously in The Annals of Thoracic Surgery and The Journal of Thoracic and Cardiovascular Surgery.

J Thorac Cardiovasc Surg 2001;121:840-1

12/1/113739

doi:10.1067/mtc.2001.113739 nologies. Because of the large number of surgeons involved, the problem of postgraduate education in new technology is even more complicated.

Whose role is it, or should it be, to design and manage instructional programs in the use of new technology? In the past, technical education in the use of new technology has come from a variety of sources including industry, ad hoc meetings (often supported by industry), visits by surgeons to institutions further along the learning curve, word of mouth, and, to a lesser extent, the professional societies. The annual meetings of The American Association for Thoracic Surgery (AATS) and the Society of Thoracic Surgeons (STS) have been effective in providing conceptual education, but the annual meeting format does not lend itself well to detailed technical training. 
Our professional societies play multiple roles, but one fundamental reason for their existence has been to maintain standards in the practice of cardiothoracic surgery. Does the goal of maintaining standards include a role in providing technical education in the use of new technology?

In an effort to examine this question, a grant has been obtained from the Foundation for Advanced Medical Education (FAME) through the Philadelphia Health Care Trust. The intent of this grant is to fund a demonstration project for technical education in offpump (beating heart) coronary bypass surgery. The details of this program have been developed by a joint committee of the AATS and STS (the Committee on New Technology Assessment) and will be administered through the STS. The planned training program includes didactic sessions, live animal and cadaver training, observational visits to the institutions of surgeons who are experienced in off-pump surgery, and visits by those surgeons (preceptors) to the trainees' home institutions to observe the trainees performing off-pump surgery. It is anticipated that the trainees will be surgeons with experience in coronary bypass surgery but without extensive experience in off-pump surgery. Most of the trainees' expenses will be borne by the grant. Instructors and preceptors in the course will be selected by the committee on the basis of experience with off-pump surgery and will represent a spectrum of institutions.

The purposes of this effort are to provide training in off-pump surgery, to serve as a template for future technical education, and to give the professional societies experience in dealing with this issue. Even after completion of this pilot project many questions will remain, including educational strategies, funding, and the sustainability of these efforts. But this is a start. Lurking on the horizon are changes in minimally invasive surgery, robotics, and permanent implantable assist devices-technologies that will stress our current concepts of postgraduate training and increase the price paid for long learning curves. In part, the current project is an attempt to be ready for these future challenges. Surgeons wishing to participate as trainees should contact The Society of Thoracic Surgeons, ATTN.: Donald Turney, 401 N Michigan Avenue, Chicago, IL 60611, for application forms.

Received for publication Nov 22, 2000; accepted for publication Dec 13, 2000.

Address for reprints: Bruce W. Lytle, MD, Department of Thoracic/Cardiovascular Surgery, The Cleveland Clinic Foundation, 9500 Euclid Ave, F-25, Cleveland, OH 44195. 